\title{
Embryo-induced transcriptome changes in bovine endometrium reveal species-specific and common molecular markers of uterine receptivity
}

\author{
Stefan Bauersachs ${ }^{1,2}$, Susanne E Ulbrich ${ }^{3}$, Karin Gross ${ }^{1,2}$, Susanne E M Schmidt ${ }^{1}$, \\ Heinrich H D Meyer ${ }^{3}$, Hendrik Wenigerkind ${ }^{4}$, Margarete Vermehren ${ }^{5}$, Fred Sinowatz ${ }^{5}$, \\ Helmut Blum ${ }^{2}$ and Eckhard Wolf ${ }^{1,2}$ \\ ${ }^{1}$ Institute of Molecular Animal Breeding and Biotechnology, and ${ }^{2}$ Laboratory for Functional Genome Analysis \\ (LAFUGA), Gene Center, Ludwig-Maximilians University, Feodor-Lynen-Str. 25, 81377 Munich, Germany, \\ ${ }^{3}$ Physiology-Weihenstephan, Technical University of Munich, Weihenstephaner Berg 3, 85354 Freising, Germany, \\ ${ }^{4}$ Bavarian Research Center for Biology of Reproduction, Hackerstr. 27, 85764 Oberschleissheim, Germany and \\ ${ }^{5}$ Institute of Veterinary Anatomy, Histology and Embryology, Ludwig-Maximilians University, Veterinaerstr. 13, \\ 80539 Munich, Germany
}

Correspondence should be addressed to E Wolf; Email: ewolf@Imb.uni-muenchen.de

\begin{abstract}
The endometrium plays a central role among the reproductive tissues in the context of early embryo-maternal communication and pregnancy. This study investigated transcriptome profiles of endometrium samples from day 18 pregnant vs non-pregnant heifers to get insight into the molecular mechanisms involved in conditioning the endometrium for embryo attachment and implantation. Using a combination of subtracted cDNA libraries and CDNA array hybridisation, 109 mRNAs with at least twofold higher abundance in endometrium of pregnant animals and 70 mRNAs with higher levels in the control group were identified. Among the mRNAs with higher abundance in pregnant animals, at least 41 are already described as induced by interferons. In addition, transcript levels of many new candidate genes involved in the regulation of transcription, cell adhesion, modulation of the maternal immune system and endometrial remodelling were found to be increased. The different expression level was confirmed with real-time PCR for nine genes. Localisation of mRNA expression in the endometrium was shown by in situ hybridisation for AGRN, LGALS3BP, LGALS9, USP18, PARP12 and BST2. A comparison with similar studies in humans, mice, and revealed species-specific and common molecular markers of uterine receptivity.

Reproduction (2006) 132 319-331
\end{abstract}

\section{Introduction}

In cattle, implantation of the embryo takes place after day 18 of gestation and, like in other ruminants, an epitheliochorial placenta is formed through a relatively non-invasive placentation process. In contrast to primates and rodents, in cattle the time of implantation is late, when the trophoblast layer of the conceptus is elongated and fills out the entire 'pregnant' uterine horn. Interferon- $\tau$ (IFNT) has been identified as the major embryonic pregnancy recognition signal in ruminants, which prevents the induction of luteolysis, thus enabling the establishment of a pregnancy (Bazer et al. 1997). This is mediated by the suppression of the expression of oestrogen receptor- $\alpha$ (ESR1) and oxytocin receptor (OXTR) mRNA, which prevents the production and pulsatile secretion of luteolytic prostaglandin $F_{2 \alpha}$ resulting in the maintenance of the ovarian corpus luteum and progesterone production (Spencer \& Bazer 1996). Maximum secretion of IFNT was observed on day 17 (Bazer et al. 1997) in parallel to the time of maternal recognition of pregnancy. IFNT is a member of the type-I IFNs (Martal et al. 1998) and is most similar to human IFN- $\omega$ (Roberts et al. 1999). IFNT mediates its effects in bovine endometrium by binding to endometrial type-I IFN receptors (Li \& Roberts 1994), leading to the activation of the JAK-STAT pathway (Binelli et al. 2001). A number of genes have already been described as induced by IFNT in the endometrium of cattle or sheep, such as IFN-stimulated gene 15 (ISG15), 2'-5'oligoadenylate synthetase $(O A S)$, bovine ubiquitinactivating E1-like enzyme (UBE1L), members of the 
1-8 family (IFITM1-3), MX protein (MX1), granulocytemacrophage colony-stimulating factor-1 (GMCSF1), IFN regulatory factors 1 (IRF1) and 2 (IRF2) and signal transducer and activator of transcriptions 1 (STAT1) and 2 (STAT2) (Thatcher et al. 2001, Wolf et al. 2003). Recently, a database of IFN-stimulated genes revealed by microarray experiments has been established (de Veer et al. 2001).

Although the major embryonic pregnancy signal (IFNT) has been known for a long time, the detailed mechanisms of the preparation of the endometrium for the implantation of the conceptus are not completely understood. To investigate these mechanisms in the bovine endometrium, a large project was started using holistic approaches at the transcriptome and the proteome levels (Wolf et al. 2003). The present study is a part of this project and uses a combination of subtracted cDNA libraries and CDNA array hybridisation to identify mRNAs of genes differentially regulated in the bovine endometrium by the presence of a conceptus on day 18 of gestation - the preimplantation stage. In mice, rhesus monkey and humans, microarray analyses have been performed to find mRNAs of differentially expressed genes during the embryonic implantation or the window of implantation (Reese et al. 2001, Kao et al. 2002, Sun et al. 2004). These studies revealed numerous genes that are regulated during the preparation of the endometrium for the implantation of the embryo. However, due to the different types (epitheliochorial placentation in cattle vs haemochorial placentation in primates and rodents) and the different times of implantation in cattle and other ruminants compared to these species, a transcriptome study of bovine endometrium at the preimplantation stage is of particular importance. Previously, we have identified genes with higher mRNA levels in the bovine endometrium of day 18 pregnant cows (Klein et al. 2006). As biological model, monozygotic twin pairs were used; one twin received two embryos produced in vitro, whereas the other received a sham transfer and served as nonpregnant control. In comparison to Klein et al., the present study investigated transcriptome changes in the endometrium, which were induced by an in vivo embryo derived from artificial insemination. Furthermore, 140 additional transcripts, which are increased or decreased in pregnant endometrium, were identified considerably expanding the set of genes differentially expressed in bovine endometrium at the preimplantation stage.

\section{Experimental animals}

All experiments with animals were conducted with permission from the local veterinary authorities and in accord with accepted standards of Humane Animal Care.

\section{Materials and Methods}

\section{Pretreatment of animals and collection of endometrial tissue samples}

Ten cyclic heifers (Bos taurus, Deutsches Fleckvieh, Simmental) between 17 and 22 months old were synchronised by injecting intramuscularly a single dose of $500 \mu \mathrm{g}$ Cloprostenol (Estrumate; Essex Tierarznei, Munich, Germany) at dioestrus. Animals were observed for sexual behaviour (i.e. toleration, sweating and vaginal mucus) to determine standing heat, which occurred around $60 \mathrm{~h}$ after Estrumate injection. In addition, the animals were checked with ultrasoundguided follicle monitoring. Blood samples were taken on days 20 and 0 of the oestrous cycle and just before slaughtering to determine serum progesterone $\left(\mathrm{P}_{4}\right)$ levels (Prakash et al. 1987). The first group of animals was inseminated with cryo-conserved sperm (ejaculate+ diluter, 1:10) at oestrus. Animals were slaughtered on day 18 of gestation and intact conceptuses were detected in the ipsilateral uterine horns of the animals used for gene expression analysis $(n=4)$. Control animals $(n=6)$ were inseminated with the supernatant of centrifuged sperm and also slaughtered on day 18 of the oestrous cycle. No conceptus was found in control animals. Sperm was derived from the same bull. The uterus was prepared and opened longitudinally. In pregnant animals, the conceptus was localised and carefully removed. Tissue samples of the caudal part of the ipsilateral uterine horn were used for transcriptome analyses. Samples were carefully cut from the lamina propria of the intercaruncular endometrium with a scalpel and immediately transferred into vials containing $4 \mathrm{ml}$ RNAlater (Ambion, Huntingdon, Cambridgeshire, UK) and incubated overnight at $4{ }^{\circ} \mathrm{C}$. Samples were stored at $-20^{\circ} \mathrm{C}$ until further processing. Tissue samples for in situ hybridisation were collected from the same animal.

\section{Generation of subtracted cDNA libraries and cDNA array hybridisation}

The production of subtracted libraries was done according to the suppression subtractive hybridisation (SSH) method (Diatchenko et al. 1996). Total RNA from endometrial tissue samples of the ipsilateral caudal part of the uterus was isolated using Trizol reagent (Invitrogen) according to the manufacturer's recommendations. The quantity and quality of total RNA were determined by spectrometry and agarose gel electrophoresis respectively. Sixty micrograms of pooled total RNA (corresponding to approximately $1.8 \mu \mathrm{g}$ mRNA) were used for the preparation of subtracted cDNA libraries for pregnant and control animals respectively. The construction of the libraries was done as previously described (Bauersachs et al. 2003, Bauersachs et al. 2004) with the modification that no additional driver 
cDNA was added at the second step of subtractive hybridisation. For every library, 1536 cDNA clones were randomly picked, the cDNA fragments amplified via PCR and spotted by a spotting robot (Omnigrid Accent; Gene Machines, San Carlos, CA, USA) onto positively charged nylon membranes (Nytran Supercharge; Schleicher\&Schuell, Dassel, Germany) (array size, 20× $50 \mathrm{~mm}$ ). Array hybridisation with ${ }^{33}$ P-labelled cDNA probes was done as previously described (Bauersachs et al. 2004). The array hybridisation with ten cDNA probes corresponding to the ten animals was processed simultaneously.

\section{Analysis of array data}

Array evaluation was done using AIDA Image Analyzer software (Version 3.52; Raytest, Straubenhardt, Germany). Background was subtracted with the 'Lowest grid dot' function. Raw data obtained by AIDA Array software were exported to Microsoft Excel and normalised to the median of the signals of internal reference cDNAs (60-70 cDNAs that show the lowest coefficient of variation over all hybridisations) for each array. Normalised data were $\log _{2}$-transformed and analysed with the significance analysis of microarrays method (SAM) (Tusher et al. 2001). Cut-off was set to twofold and false discovery rate (FDR) to $1 \%$. If a gene was represented on the array by more than one cDNA fragment, the mean signal ratio was calculated. The data discussed in this publication have been deposited in National Center for Biotechnology Information's (NCBIs) Gene Expression Omnibus (GEO, http://www.ncbi. nlm. nih.gov/geo/) and are accessible through GEO Series accession number GSE3225.

\section{Sequencing of cDNAs with differential hybridisation signals and data analysis}

cDNA fragments set as interesting were sequenced directly from spotting solutions using a pipetting robot (Multiprobe II Automated Liquid Handling System; Perkin Elmer, Rodgau, Germany) and automated DNA sequencing (3100-Avant Genetic Analyzer; Applied Biosystems, Langen, Germany). The resulting sequences were compared with public sequence databases using the basic local alignment search tool ('discontiguous Mega BLAST') at the NCBI (www.ncbi.nlm.nih.gov/ blast/blast.cgi). cDNAs without similar entries in the ' $n r^{\prime}$ database were in addition compared with the 'est' database or the bovine genome (http://www.ensembl. org/Bos_taurus/blastview). For weak similarities to human genes, similarity at the protein level was also checked. Based on the human orthologous genes, the most specific gene ontology (GO) categories were determined using the NetAffx Analysis Center (Affymetrix, High Wycombe, UK). The resulting data were supplemented with additional information from Entrez Gene (www.ncbi.nlm.nih.gov/entrez/query.fcgi?db= gene) and from the literature, respectively. Enriched GO categories were identified with GO tree machine (GOTM) (Zhang et al. 2004) (all human genes as reference gene list) and Bibliosphere (Version 6.03; GenomatiX, Munich, Germany). The $z$-score revealed by Bibliosphere was calculated as follows: $z=$ (observed expected)/s.D.(observed). Comparison to other studies was based on human gene IDs for studies in humans and rhesus monkey and on the official gene name for studies in the mouse and in sheep. Gene lists of the corresponding papers were translated with Bibliosphere or other tools to obtain the gene ID and the official gene symbol. The lists were then compared in Microsoft Excel.

\section{Real-time RT-PCR}

The same RNA samples as for array hybridisation were used. A two-step quantitative real-time RT-PCR (qPCR) was undertaken as described recently (Klein et al. 2006). Quantitative real-time PCRs using the LightCycler DNA Master SYBR Green I protocol (Roche) were performed. The following primers were used to amplify the specific fragments referring to selected regulated genes (length of the PCR products in square brackets): AGRN (for 5'-TATGAGTGCCTGTGTCCTGC; rev 5'-CTGCTGGACTCGATGTAGGTC [123 bp]); BST2 (for 5'-ACACTGAAC CGTTGTCCTCC; rev 5'-GGGCAGTGGACTCTCTGAAG [145 bp]); C17orf27 (for 5'-AAGAAGGAAGAAAGCCAGCTTC; rev 5'-GACTACTGCATGCTGAGAGGG [104 bp]); DKK1 (for 5'-GCGTCACGCTATGTGCTG; rev 5'-GCTTTCAATAATGGTTTCCTCG [109 bp]); LGALS9 (for 5'-CTTCAACGAGAATGCGGTG; rev 5'-TTGAAGCAGTGCCCTTCAC [141 bp]); STAT1 (for 5'-CTCATTAGTTCTGGCACCAGC; rev 5'-CACACGAAGGTGATG AACATG [108 bp]); DTX4 (for 5'-GTCTCTTCCCGAGATGCTTG; rev 5'-CATGAGAGAGAGGGCAGAGG [147 bp]); MTA2 (for 5'-CAGCAGCTCTTCTTGCAGG; rev 5'-AGTGCTTTGCTCAGCAGTCTC [150 bp]); OXTR (for 5'-ACGGTGTCTTCGACTGCTG; rev 5'-GGTGGCAAGGACGATGAC [110 bp]) and polyubiquitin (Z18245) as a housekeeping gene (for 5'-AGATCCAGGATAAGGAAGGCAT; rev 5'-GCTCCACCTCCAGGGTGAT [198 bp]).

All the amplified PCR fragments were sequenced to verify the resulting PCR product. Thereafter, the specific melting point (MP) of the amplified product carried out within the LightCycler standard PCR protocol served as a verification of the product identity. The annealing temperature was $60{ }^{\circ} \mathrm{C}$ for all the PCRs. The MPs and the appropriate fluorescence acquisition (FA) points for quantification within the fourth step of the amplification segment were as follows: polyubiquitin, AGRN (MP $88^{\circ} \mathrm{C}$, FA $\left.84^{\circ} \mathrm{C}\right)$, BST2 (MP $86^{\circ} \mathrm{C}$, FA $\left.75^{\circ} \mathrm{C}\right)$, C17orf 27 (MP $79^{\circ} \mathrm{C}$, FA $75^{\circ} \mathrm{C}$ ), DKK1 (MP $83^{\circ} \mathrm{C}$, FA $79^{\circ} \mathrm{C}$ ), LGALS9 (MP $89^{\circ} \mathrm{C}$, FA $86^{\circ} \mathrm{C}$ ), STAT1 (MP $87^{\circ} \mathrm{C}$, FA 
$\left.84^{\circ} \mathrm{C}\right)$, DTX4 (MP $\left.86{ }^{\circ} \mathrm{C}, \mathrm{FA} 83^{\circ} \mathrm{C}\right), \mathrm{MTA} 2\left(\mathrm{MP} 90^{\circ} \mathrm{C}\right.$, FA $86^{\circ} \mathrm{C}$ ) and OXTR (MP $87^{\circ} \mathrm{C}$, FA $83^{\circ} \mathrm{C}$ ). As negative controls, water was used instead of cDNA. The cycle number required for achieving a definite SYBR Green fluorescence signal (=crossing point, $\mathrm{CP}$ ) was calculated by the second derivative maximum method (LightCycler software version 3.5.28). The CP is correlated inversely with the logarithm of the initial template concentration.

\section{Data analysis of real-time RT-PCR}

Results are presented as means \pm s.E.M. $(n=4$ and 6 respectively) (Table 3 ). The housekeeping gene polyubiquitin showed no statistical difference between pregnant and control animals. Therefore, the CPs determined for the target genes were normalised against polyubiquitin $(\Delta \mathrm{CP})$. Differences between pregnant and control animals are expressed by the $\Delta \Delta C P$ as well as the 'mean fold changes qPCR' (Livak \& Schmittgen 2001). The normal distribution was tested by the KolmogorowSmirnov method, followed by a Student's $t$-test to find significant differences between pregnant and control animals.

\section{In situ hybridisation}

In situ hybridisation was performed as previously described (Bauersachs et al. 2005). The sequences of the antisense oligonucleotides were as follows: $A G R N$, 5'-TCAAAGGCCAGTGCGTCCAG; BST2, 5'-CACACTG AACCGTTGTCCTC; BUBP43 (USP18), 5'-TCCCAGCT AACAGATCACTG; LGALS3BP, $5^{\prime}$-ACTGCCCTTCA CAGTGTCAT; LGALS9, 5'-AGCAGTGCCCTTCACA CATG and PARP12, 5'-AGCACAGGTATTCAGATCTCA. Negative controls were done by omitting the oligonucleotide probe and by hybridisation with sense oligonucleotide probes (complementary sequences of the antisense oligonucleotides).

\section{Results}

\section{Identification of differentially expressed genes and validation by $\mathbf{Q P C R}$}

Total RNA was isolated from endometrial tissue samples derived from the caudal ipsilateral uterine horn of pregnant or non-pregnant heifers respectively. Samples were collected on day 18 of gestation from ten animals (pregnant, $n=4$; control, $n=6$ ). The determination of serum $\mathrm{P}_{4}$ levels revealed that the pregnant animals displayed high serum $\mathrm{P}_{4}$ levels $(2.3-5.9 \mathrm{ng} / \mathrm{ml})$ and the control animals had significantly lower serum $\mathrm{P}_{4}$ levels $(0.4-1.6 \mathrm{ng} / \mathrm{ml})$ respectively at the time of slaughtering.

For the enrichment of cDNAs of differentially expressed genes, two subtracted cDNA libraries were produced for pregnant and control animals respectively, starting from a pool of RNA samples from each group. One thousand five hundred and thirty-six randomly picked cDNA clones of each library were analysed by cDNA array hybridisation with the endometrial tissue samples to detect cDNAs, which reveal different signals between the two experimental groups.

Sequence analysis of 480 cDNA fragments, which resulted from the SAM analysis (fold change $\geq 2.0$, $\mathrm{FDR}=1 \%$ ) revealed 109 different transcripts with higher levels in pregnant animals (in the following referred to as upregulated genes). Nine different major histocompatibility complex (MHC) class-1 mRNAs were counted only as one transcript (Table 1 which can be viewed at http://www.reproduction-online.org/supplemental/). In the control group, 70 mRNAs were detected with higher concentrations compared to the pregnant group (in the following referred to as downregulated genes) (Table 2 which can be viewed at http://www.reproductiononline.org/supplemental/). The mean fold-up ratio was 6.0 and ranged from 2- (cut-off) to 103-fold in comparison to a mean fold-down of 5.1 that ranged between 2- and 120-fold. Among the upregulated genes, at least 41 have already been described as induced by IFNs. Twenty-four of the downregulated genes were previously detected as upregulated at oestrus compared to the dioestrus stage in bovine endometrium (Bauersachs et al. 2005).

Nine genes were selected for mRNA quantification by qPCR (Table 3). The results obtained by array hybridisation were clearly confirmed and more accurate gene expression differences were obtained. Higher expression differences were observed by qPCR in particular for BST2, DKK1, LGALS9 and STAT1.

\section{GO classification of the genes with higher mRNA levels in pregnant animals}

Based on data for the corresponding human genes, the obtained genes were assigned to GO categories to identify relevant functional groups and prominent biological processes. Figure 1 gives a simplified overview for the GO categories based on the major categories 'biological process' and 'molecular function' for the upregulated genes. The subcategories with the highest numbers of genes were: immune response, hydrolase activity, nucleotide binding, signal transduction, transferase activity, transport and peptidase activity. Table 4 (which can be viewed at http://www.reproductiononline.org/supplemental/) shows the assignment of genes with higher mRNA levels in pregnant animals to biological processes and molecular functions in more detail for the most interesting categories and considers that many genes can appear in different subcategories providing different (functional) views on a single gene.

GOs that are probably enriched, and therefore, may be particularly interesting, are shown in Fig. 2 for the upregulated genes. Enriched means that there are much 
Table 3 Quantification of mRNA levels for selected genes by quantitative real-time RT-PCR (qPCR).

\begin{tabular}{|c|c|c|c|c|c|c|c|c|c|}
\hline \multirow[b]{2}{*}{ Gene } & \multicolumn{2}{|c|}{ CP mean/s.E.M. } & \multicolumn{2}{|c|}{$\Delta \mathrm{CP}$ mean/s.E.M. } & \multirow[b]{2}{*}{$\Delta \Delta C P$} & \multicolumn{2}{|c|}{ Mean fold change } & \multirow{2}{*}{$\begin{array}{c}P \text {-value } \\
\text { qPCR }\end{array}$} & \multirow{2}{*}{$\begin{array}{c}q \text {-value } \\
\text { array }\end{array}$} \\
\hline & Pregnant & Control & Pregnant & Control & & qPCR & Array & & \\
\hline Ubiquitin & $17.9 \pm 0.1$ & $17.9 \pm 0.1$ & - & - & - & - & - & - & - \\
\hline AGRN & $21.7 \pm 0.2$ & $24.1 \pm 0.2$ & $3.6 \pm 0.3$ & $6.3 \pm 0.2$ & 2.7 & 6.4 & 4.9 & $<0.001$ & 0.00 \\
\hline BST2 & $20.3 \pm 0.6$ & $24.0 \pm 0.5$ & $2.2 \pm 0.5$ & $6.3 \pm 0.5$ & 4.1 & 16.7 & 8.3 & $<0.001$ & 0.00 \\
\hline C17orf27 & $19.1 \pm 0.3$ & $22.0 \pm 0.3$ & $1.0 \pm 0.4$ & $4.2 \pm 0.4$ & 3.2 & 9.4 & 5.4 & $<0.001$ & 0.00 \\
\hline DKK1 & $21.9 \pm 0.4$ & $29.2 \pm 1.0$ & $3.8 \pm 0.5$ & $11.4 \pm 1.0$ & 7.6 & 191.2 & 11.9 & $<0.001$ & 0.00 \\
\hline LGALS9 & $23.0 \pm 0.2$ & $25.7 \pm 0.5$ & $4.9 \pm 0.1$ & $7.9 \pm 0.5$ & 3.0 & 8.1 & 3.7 & $<0.001$ & 0.00 \\
\hline STAT1 & $19.2 \pm 0.1$ & $22.1 \pm 0.2$ & $1.1 \pm 0.2$ & $4.3 \pm 0.2$ & 3.2 & 9.2 & 2.4 & $<0.001$ & 0.00 \\
\hline DTX4 & $24.6 \pm 0.0$ & $21.8 \pm 0.2$ & $6.6 \pm 0.1$ & $4.0 \pm 0.2$ & -2.5 & -5.8 & -4.4 & $<0.001$ & 0.00 \\
\hline MT2A & $24.6 \pm 0.2$ & $21.8 \pm 0.6$ & $6.5 \pm 0.3$ & $4.0 \pm 0.4$ & -2.5 & -5.7 & -6.3 & $<0.001$ & 0.31 \\
\hline OXTR & $28.3 \pm 0.4$ & $21.6 \pm 0.2$ & $10.2 \pm 0.4$ & $3.8 \pm 0.3$ & -6.4 & -84.3 & -120 & $<0.001$ & 0.00 \\
\hline
\end{tabular}

$\mathrm{CP}$, crossing point; $\Delta \mathrm{CP}, \mathrm{CP}-\mathrm{CP}_{\text {ubi }} ; \Delta \mathrm{CP}, \Delta \mathrm{CP}_{\text {control }}-\Delta \mathrm{CP}_{\text {pregnant }}$.

more genes observed for a category than expected by chance. For the categories shown in Fig. 2, the $z$-score provided by Bibliosphere software was at least 2.5 or the $P$-value calculated by GOTM was less than 0.006 respectively. In addition to the major categories in Fig. 1, the following biological processes or molecular functions were clearly overrepresented: complement activation, regulation of apoptosis, I- $\mathrm{B}$ kinase/NF- $\kappa \mathrm{B}$ cascade, protein amino acid ADP-ribosylation, endonuclease activity and ATP-dependent helicase activity.

\section{Comparison to related studies}

The identified genes were compared to two recent studies of transcriptome changes in the preimplantation phase in cattle (Klein et al. 2006) and sheep (Gray et al. 2006) (Table 5 which can be viewed at http://www. reproduction-online.org/supplemental/). Twelve genes were identified in all three studies and are all known as type-I IFN-induced genes. In the study of monozygotic twins using cows on day 18 of pregnancy, only genes with higher mRNA levels in pregnant endometrium were analysed. The overlap with this study was 39 genes and the mRNA expression differences were all consistent. Gray et al. compared day 14 pregnant, cyclic and uterine gland knockout ewes as well as different treatment groups (progesterone and/or IFNT and/or antiprogestin and/or control proteins). The overlap with this study was 23 genes. Except for four genes (ACTB, C17orf27, GRP and HSPA5), mRNA expression differences were in line compared with the study in the sheep.

Furthermore, the gene lists revealed by the present study were compared to the results of eight related studies in other species, which show an invasive type of embryo implantation. The six studies of human endometrium compared mRNA levels during the putative window of implantation (days 6-10 after luteinizing hormone (LH) surge) with earlier stages of the cycle ranging from 6 days before and 4 days after the $\mathrm{LH}$ surge (Carson et al. 2002, Kao et al. 2002, Borthwick et al.
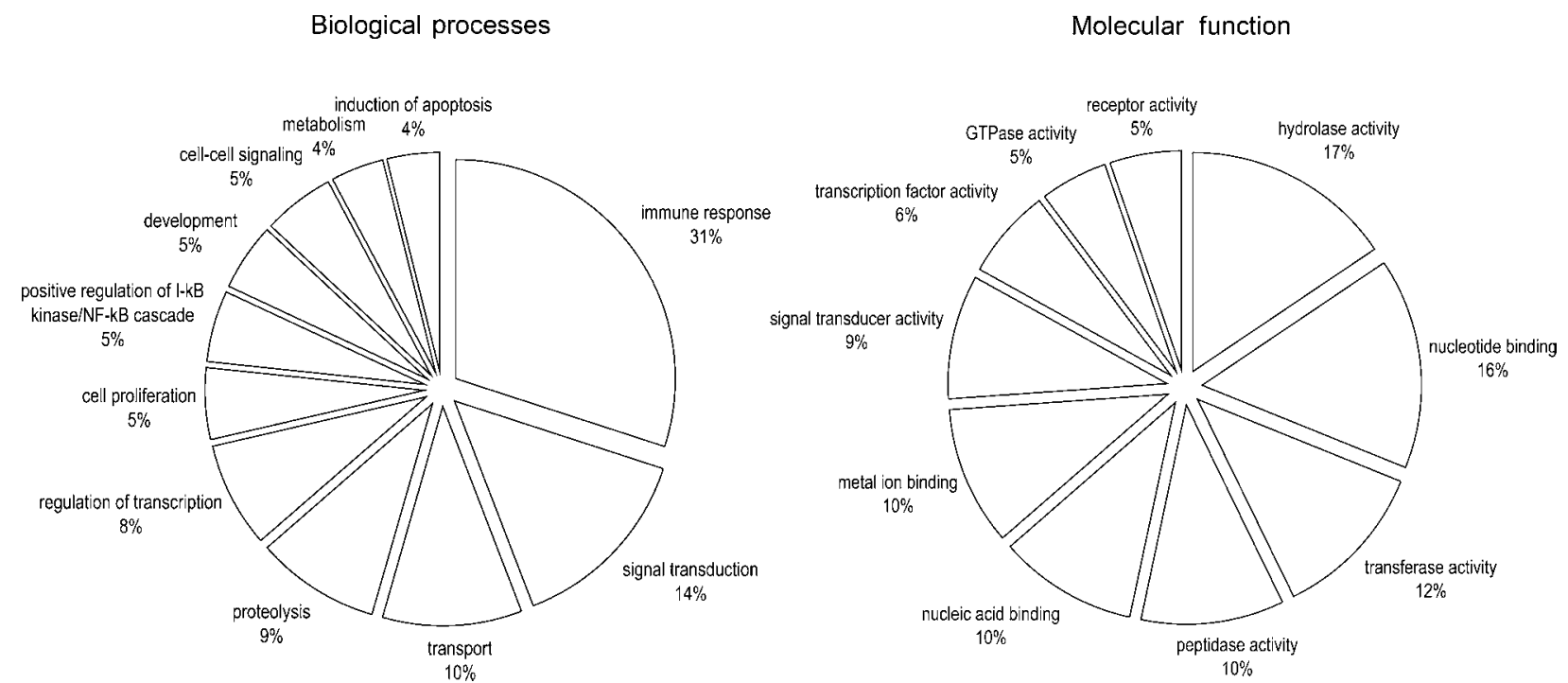

Figure 1 Classification of the genes of known function identified as upregulated in the endometrium of day 18 pregnant animals based on the gene ontologies (GOs) Biological Process and Molecular Function. Multiple naming is possible. 


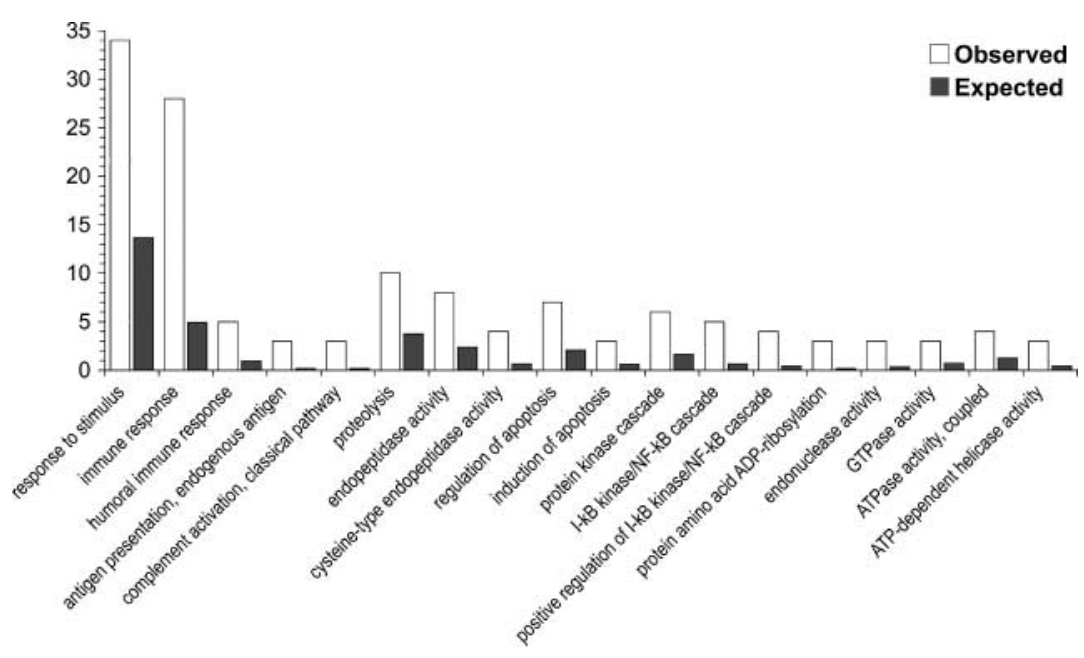

Figure 2 Enriched GO terms for genes upregulated in the endometrium of pregnant animals. Observed vs expected numbers of genes for relevant $\mathrm{GO}$ terms are shown.
2003, Riesewijk et al. 2003, Mirkin et al. 2005). Ace \& Okulicz (2004) compared similar stages in the rhesus monkey. Another two studies analysed gene expression profiles during embryo implantation (Reese et al. 2001) and oestrogen-induced genes (Ho et al. 2004) in mouse endometrium respectively. Fifty-five genes were found overlapping with at least one of these studies (Table 6 which can be viewed at http://www.reproductiononline.org/supplemental/). Of these genes, 29 were regulated in the same direction, 17 were contrary and 7 were detected as 'expressed' only.

\section{Localisation of mRNA expression by in situ hybridisation}

In situ hybridisation with biotinylated oligo-probes was used to detect the mRNAs of six genes that were upregulated in the pregnant animals (Fig. 3). AGRN, $\angle G A L S 3 B P$ and LGALS9 were selected due to their potential role in cell adhesion. USP18 and PARP12 stand for protein modification and $B S T 2$ has probably a role in immune modulation. A specific pattern of mRNA distribution was found for each of these genes (Table 7). The hybridisation signal was always confined to cells of the endometrium. No mRNA staining was seen in the myometrium or the serosa. No specific signal was observed in sections hybridised with the sense strand or the section that was incubated with buffer only instead of the oligo-probes. Strong staining for $A G R N$, $\angle G A L S 3 B P$ and USP18 was found in the luminal epithelium of the uterus, whereas a somewhat lesser intensity was seen for PARP12 and LGALS9. For BST2, only a weak content of mRNA was found. The superficial glands generally showed only a weak to moderate reaction for all the genes studied. Only for PARP12, a distinct staining was seen both in the superficial and deep uterine glands. The deep glands also showed a pronounced staining for USP18 mRNA. Most fibroblasts of the endometrium displayed a distinct hybridisation signal for PARP12 and a somewhat weaker staining for BST2 and USP18.

\section{Discussion}

The characterisation of the molecular mechanisms of attachment and implantation of the bovine conceptus are of particular importance towards the identification of reasons for embryonic mortality in the preimplantation period. To identify genes involved in these processes, mRNA expression profiles of bovine endometrium on day 18 of pregnancy were compared to control samples collected on day 18 of the oestrous cycle. Both groups of animals were prepared under identical conditions to avoid influences of differences in animal treatment on gene expression profiles. To achieve this, the control animals were inseminated with the supernatant of centrifuged sperm of the same bull. However, the heifers used for the collection of endometrial samples showed lower serum $\mathrm{P}_{4}$ levels in the control group. This is reflected by the upregulation of genes in the control group, which are characteristic for endometrial remodelling during oestrus (see also below). Nevertheless, for the establishment of pregnancy and the implantation of an embryo both are important, the signalling of the embryo and the maintenance of high serum $\mathrm{P}_{4}$ levels. For this study, the analysis of day 18 was the most important, as it is the time immediately before conceptus implantation. It has to be considered further that the decision for the progression of the cycle (i.e. luteal regression) is already made around day 16 when OXTR mRNA starts rising during the normal oestrous cycle.

Differences in mRNA levels were identified using a combination of subtracted cDNA libraries and cDNA array hybridisation. The comparison of four pregnant animals vs six control animals revealed 179 genes with differences in mRNA levels of twofold or more 


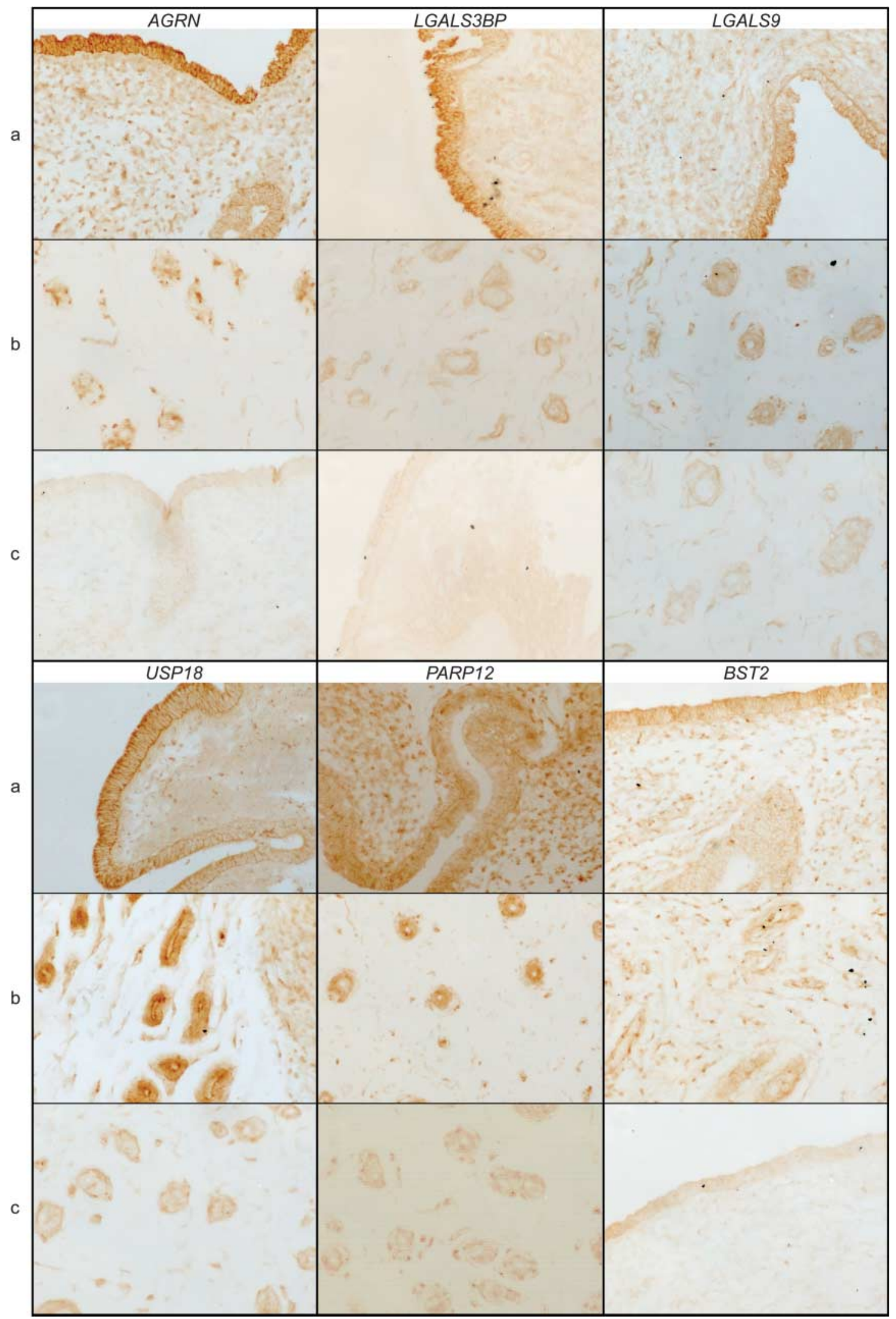

Figure 3 In situ hybridisation with endometrial tissue samples of day 18 pregnant animals. Endometrial sections near the epithelial surface (a), of the deep uterine glands (b) and the corresponding negative (sense) controls (c) are shown. Magnification, 120-fold. 
Table 7 Results of in situ hybridisation of bovine endometrium.

\begin{tabular}{lllll}
\hline & & \multicolumn{2}{c}{ Glandular epithelium } & \\
\cline { 3 - 4 } Gene & $\begin{array}{l}\text { Luminal } \\
\text { epithelium }\end{array}$ & Superficial & $\begin{array}{l}\text { Deeper } \\
\text { glands }\end{array}$ & Stromal cells \\
\hline AGRN & +++ & + & + & + \\
LGALS3BP & +++ & $(+)$ & $(+)$ & - \\
LGALS9 & + l+t & $(+)$ & $(+)$ & $(+)$ \\
BUBP43 & +++ & + & ++ & + \\
(USP18) & & & & ++ \\
PARP12 & ++ & ++ & ++ & + \\
BST2 & + & + & + & + \\
\hline
\end{tabular}

- , no staining; $(+)$, weak staining; + , moderate staining; ++ , distinct staining; +++ , strong staining

$(\mathrm{FDR}=1 \%)$. Nine mRNAs were selected for the verification of the array results and exact quantification by qPCR. Array results were clearly confirmed for these mRNAs. Very high expression differences were underestimated by the array approach for some genes for different reasons (see also Bauersachs et al. 2004). Although there was virtually no visible signal of the control probes for $D K K 1$, the array evaluation software calculated a signal value because of a higher background at the $D K K 1$ spot compared to the selected background spot. For STAT1, the signals of the control probes were artificially elevated by a very strong signal of the neighbouring cDNA spot resulting in a decreased expression ratio.

At least 41 of the upregulated genes are known as stimulated by IFNs indicating the response of the endometrium to the embryonic IFNT. Several of these genes have already been described in the context of early pregnancy in cattle, like B2M, IFITM1 and IFITM3, ISG15, MX, OAS1 and OAS2 and STAT1 (Thatcher et al. 2001, Wolf et al. 2003), but for many of these, little information exists regarding the exact function in the context of early pregnancy.

A substantial number of genes (70 genes) with higher mRNA levels in the endometrium of the control animals is related to the physiological processes associated with the progression of the oestrous cycle. Most of these genes are coding for extracellular matrix (ECM) proteins, proteins related to ECM remodelling or proteins of the cytoskeleton reflecting oestrogeninduced changes in the endometrium. In a previous study, 24 of these genes were already detected as upregulated at oestrus compared to the dioestrus stage in bovine endometrium (Bauersachs et al. 2005). Furthermore, mRNAs like ESR1, OXTR and STC1 are related to the progression of the oestrous cycle in nonpregnant animals and downregulation of ESR1 and OXTR in the endometrium of pregnant animals as a mechanism to prevent the progression of the oestrous cycle has been shown by Spencer \& Bazer (1996). Overall, the upregulated genes appeared to be much more interesting regarding biological processes related to the preparation of the endometrium for the implantation of the embryo. Therefore, the following discussion concentrates mainly on biological processes, where particularly such genes are involved, which had higher mRNA levels in the endometrium of pregnant animals (overview in Fig. 4).

\section{Protein modification processes and NF- $\boldsymbol{B}$ cascade}

GO classification revealed many genes playing a role in protein modification processes. A couple of genes related to the so-called ISG15ylation process were found. The ubiquitin-like protein, ISG15, is suggested to play an important role in IFNT signalling (Austin et al. 2004). ISG15 is conjugated to intracellular proteins and thereby regulates their function. In the present study, mRNAs coding for two known components of the ISG15ylation system, UBE1L, the initiating enzyme (E1) for ISG15ylation (Rempel et al. 2005) and BUBP43 (USP18), an ISG15-specific protease that cleaves ISG15 from the conjugates, were found as upregulated in the endometrium of pregnant animals. The mRNA expression pattern of BUBP43 (USP18) in the bovine endometrium of day 18 pregnant animals was analysed by in situ hybridisation and is similar to that of ISG15 (Johnson et al. 1999) and UBE1L (Klein et al. 2006). Several mRNAs of putative components of the ISG15ylation system were also identified. The IFITM1-like gene and IFITM3 are coding for proteins containing a conserved E2 motif (Pru et al. 2001). C17orf27 and ISGF3G (also described as RNF31) have domains (RINGfinger (really interesting new gene) domain or IBR ubiquitin-associated domain respectively) found also in ubiquitin E3 ligases indicating that these two proteins may possess E3 ligase activity. Furthermore, the mRNAs of DTX4 and IBRDC2 were decreased in pregnant endometrium. The proteins encoded by these genes also have E3 ligase activity (Takeyama et al. 2003, Ng et al. 2003). In addition, BIRC4BP (XAF1) mRNA levels were increased in the endometrium of the pregnant animals. BIRC4BP protein has been described as an antagonist of XIAP (X-linked inhibitor of apoptosis, now named BIRC4; baculoviral IAP repeat-containing 4; Liston et al. 2001), an anti-apoptotic protein that possesses E3 ubiquitin ligase activity (MacFarlane et al. 2002). The regulation of all these genes, which are potential components of the ISG15ylation pathway, underlines the importance of this process for regulating the response of the endometrium to the embryonic IFNT.

Another protein modification process, ADP-ribosylation, is represented by three members of the poly(ADPribose) polymerase (PARP) superfamily (Ame et al. 2004). This process is involved, for example, in the regulation of membrane trafficking and actin cytoskeleton (Ame et al. 2004). The founding member PARP1 is involved in DNA repair and synthesises a polymer of ADP-ribose on various nuclear proteins associated with 


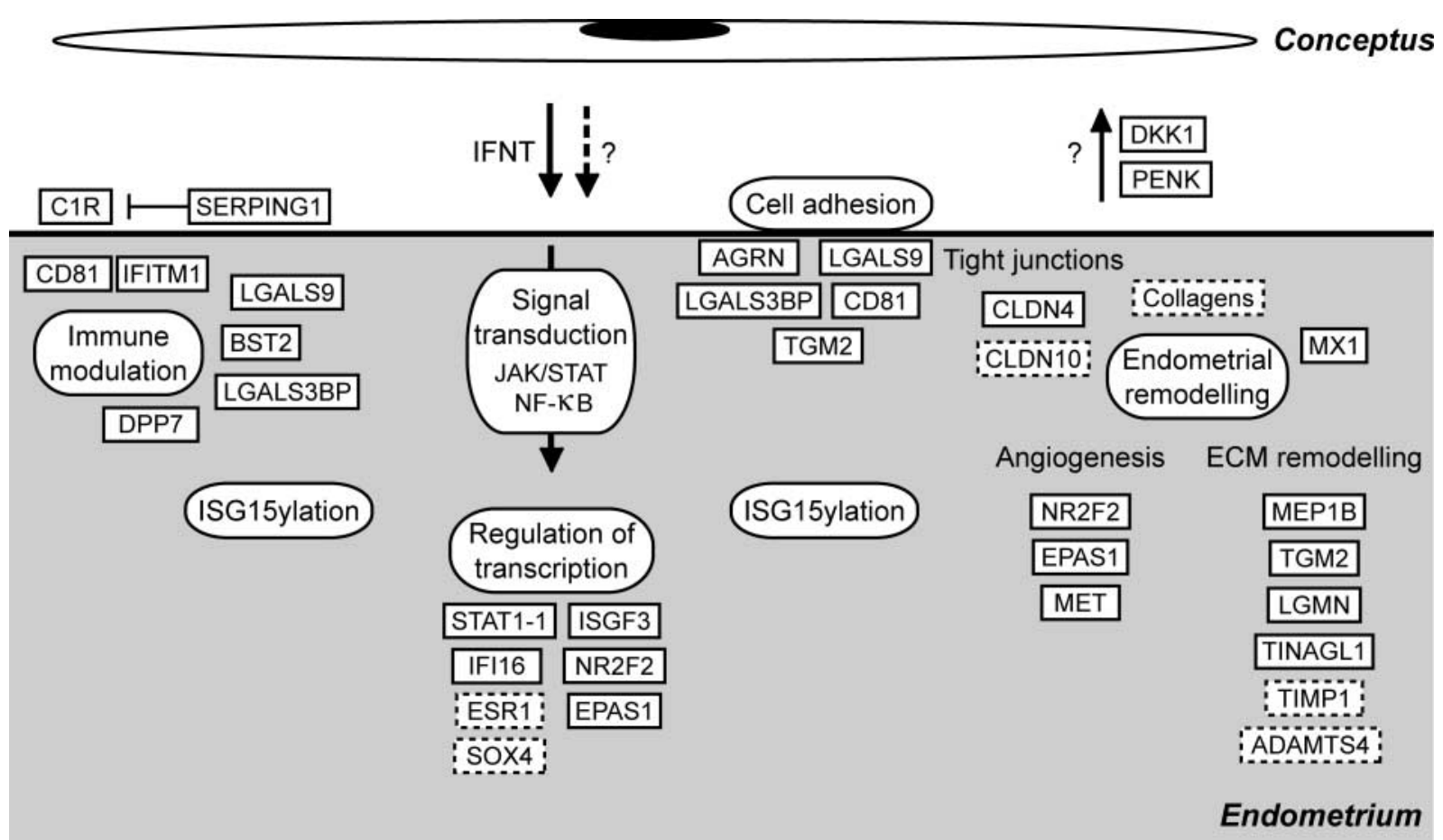

Figure 4 Schematic picture of processes and corresponding genes probably involved in the preparation of the endometrium for the attachment of the conceptus. STAT1-1, STAT1 homodimers; ISGF3, transcription factor complex consisting of STAT1/STAT2 heterodimer and ISGF3G; genes in solid boxes, upregulated in the endometrium of pregnant animals; genes in dashed boxes, downregulated in the endometrium of pregnant animals.

chromatin in response to DNA damage. Expression of PARP1 is induced by type-I IFNs. The function of the three members identified in the present study, PARP9, PARP10 and PARP12, is not well defined. PARP9 protein has been implicated in B-cell migration. A link to ubiquitination is found in the ubiquitin interaction motif (UIM) present in PARP10. PARP10 also contains a motif specific for binding to RNAs with the RNA recognition motif found in a variety of RNA-binding proteins. PARP12 contains a WWE domain found in classes of proteins associated with ubiquitination. PARP12 has three zinc fingers of the $\mathrm{C}-\mathrm{x} 8-\mathrm{C}-\mathrm{x} 5-\mathrm{C}-\mathrm{x} 3-\mathrm{H}$ type, which includes zinc finger proteins from eukaryotes involved in cell cycle or growth phase-related regulation. The UIM domain of PARP10 and the WWE domain in PARP12 also suggest a role in the regulation of ISG15ylation in the context of the present study. This is further supported by the PARP12 mRNA expression pattern in the bovine endometrium of day 18 pregnant animals, which is similar to the pattern of mRNAs coding for ISG15ylation components like ISG15, UBE1L and BUBP43.

Besides these protein modification systems, several genes were identified, which are involved in the regulation of the I- $\kappa \mathrm{B}$ kinase/NF- $\kappa \mathrm{B}$ cascade. The NF$\kappa B$ pathway has been shown to play an important role in the regulation of implantation in humans (King et al. 2001) and mouse (Nakamura et al. 2004). Together with the effects of progesterone, regulation of this pathway is probably responsible for the control of cytokine production and pro-inflammatory pathways.

\section{Regulation of transcription}

The mRNAs of six genes coding for transcription factors were found as upregulated in the endometrium of pregnant animals. ISGF3G (IRF9) and STAT1, coding for two components of the ISGF3 transcription factor complex, play a central role in IFNT signalling. ISGF3 binds to IFN-stimulated response elements found in a variety of IFN-induced genes, whereas homodimers of STAT1 bind to the so-called GAS (IFN- $\gamma$-activation site) elements (Stewart et al. 2001). IFI16 belongs to the IFN-inducible HIN-200 family (haematopoietic IFN-inducible nuclear antigens with 200 amino acid repeats) and the encoded protein can function as a transcriptional repressor. IFI16 protein is involved in the control of cell cycle regulation via modulation of TP53 (p53) and its target gene regulation (Kwak et al. 2003). For NR2F2 (COUP-TFII), a nuclear orphan receptor, active repression of the human oxytocin gene promoter was shown in the uterine epithelial cells (Chu \& Zingg 1997). In the mouse, NR2F2 haploinsufficiency results in decreased progesterone synthesis in the corpus luteum leading to reduced ability of the endometrium to support pregnancy (Takamoto et al. 2005). Since the reduced uterine stromal cell function was observed even after 
exogenous administration of progesterone, part of the $\mathrm{NR} 2 \mathrm{~F}^{+/-}$phenotype is specific to the uterus. A role of $\mathrm{NR} 2 \mathrm{~F} 2$ protein in the remodelling of the endometrium through regulation of normal vascularisation has been suggested. The haploinsufficiency model of the NR2F2 gene indicates that the encoded transcription factor is essential for normal female reproduction, in particular, for endometrial functions during the peri-implantation period. Furthermore, EPAS1 mRNA was found as upregulated in the endometrium of pregnant animals. EPAS1 codes for a basic-helix-loop-helix/PAS domain transcription factor, which has been shown to promote angiogenesis through transactivation of vascular endothelial growth factor, its receptors and several other genes (Takeda et al. 2004).

\section{Cell adhesion}

GO classification assigned six genes, which were found as upregulated in the bovine endometrium of pregnant animals to the process of cell adhesion: AGRN, CD81, CLDN4, LGALS3BP, LGALS9 and TGM2. Agrin is a heparan sulphate proteoglycan and involved in the formation of synapses of the neuromuscular junction and the immunological synapse (Bezakova \& Ruegg 2003). Agrin might have a general role in the formation of very close cell contacts and subsequent signalling between the attached cells. In situ hybridisation showed strong staining for $A G R N$ mRNA in the luminal epithelium in pregnant animals. CD81 is a member of the transmembrane 4 superfamily (tetraspanin family) and the encoded protein is involved in cell adhesion as well as in a variety of different biological processes (Levy et al. 1998). CLDN4, coding for a tight junction protein, is more likely to be responsible for the cell adhesion between epithelial cells of the endometrium regulating, for example, permeability of the epithelium (Tsukita \& Furuse 2002) (see below). The IFN-stimulated gene, LGALS3BP, codes for a cell-adhesive protein of the ECM, which self-assembles into ring-like structures and binds $\beta 1$ integrins, collagens and fibronectin (Sasaki et al. 1998). A possible role of LGALS3BP protein for adhesion of the conceptus is further supported by the in situ hybridisation results that show nearly exclusive expression in the luminal epithelium. LGALS9 (galectin 9) is also stimulated by IFNs and the encoded protein was shown to mediate cell aggregation and cell adhesion (Hirashima et al. 2004). The mRNA expression pattern in the endometrium revealed by in situ hybridisation is similar to that of LGALS3BP. A further galectin, galectin-15 was identified in ovine endometrial epithelium and hypothesised to regulate trophoblast migration, adhesion and differentiation (Gray et al. 2004). Possibly, galectin-9 has a similar role in bovine endometrium. TGM2 codes not only for a multifunctional protein that regulates cell adhesion via mediation of the interaction of fibronectin and integrins, but is also involved in the ECM remodelling, signal transduction and regulation of apoptosis (Fesus \& Piacentini 2002). Furthermore, IFITM1 might function in the adhesion of the conceptus, since IFITM1 protein was shown to regulate homotypic adhesion in B-lymphocytes (Evans et al. 1993).

\section{Remodelling of the endometrium preparing for implantation of the embryo}

As mentioned earlier, the transcription factors NR2F2 and EPAS1 may be involved in the process of endometrial remodelling during implantation of the embryo. Furthermore, elevated levels of CLDN4 mRNA were found in the endometrium of pregnant animals in the present study. Claudins are major cell adhesion molecules in tight junctions involved in intercellular sealing in simple and stratified epithelia (Tsukita \& Furuse 2002). Claudin 4 was found to selectively decrease $\mathrm{Na}^{+}$permeability in tight junctions. Furthermore, in four microarray studies of human endometrium, CLDN4 mRNA was found elevated at the window-of-implantation time (Carson et al. 2002, Kao et al. 2002, Borthwick et al. 2003, Riesewijk et al. 2003) (see below). In contrast, the mRNA level of CLDN10 is decreased in the endometrium of pregnant heifers and recently, we showed that CLDN10 mRNA is strongly upregulated in the bovine endometrium on day 0 of the oestrous cycle (Bauersachs et al. 2005). These findings suggest an important role for claudins in the preparation of the endometrium for implantation through the regulation of the architecture of the uterine epithelium. MEP1B is coding for a metalloprotease of the astacin family, which was shown to degrade components of the ECM (Kaushal et al. 1994). TGM2 was shown to be involved in wound healing and angiogenesis. Assembly and remodelling of the ECM in different tissues are mediated by cross linking various ECM proteins such as fibronectin, proteoglycans, collagen $\mathrm{V}$, osteonectin, laminin, nidogen and osteopontin and the covalent modification and activation of several growth factors. This important role of TGM2 in remodelling of the endometrium is further supported by the finding that TGM2 mRNA is upregulated in bovine endometrium on day 12 (dioestrus) compared to day 0 (oestrus) of the oestrous cycle (Bauersachs et al. 2005). Among the IFNTinduced proteins, MX1 was suggested to function as a regulator of endometrial secretion and uterine remodelling (Hicks etal. 2003). In the ovine uterus, the expression of the mRNA for hepatocyte growth factor (HGF) was detected in the stromal cells and the mRNA of its receptor (MET) exclusively in luminal and glandular epithelial cells (Chen et al. 2000). Hepatocyte growth factor has been suggested to stimulate epithelial morphogenesis in preparation for the establishment and maintenance of pregnancy, conceptus implantation and placentation. In the present study, MET mRNA level was elevated in the endometrium of pregnant animals. Legumain (LGMN), a asparaginylspecific cysteine proteinase, has been shown to activate 
progelatinase A (MMP2) in vitro and in cultured cells indicating a role in the regulation of ECM remodelling (Chen et al. 2001). Furthermore, mRNA of TIMP1, coding for a tissue inhibitor of metalloproteinases, was decreased in the endometrium of pregnant animals compared to the control group. Salamonsen et al. suggested an important contribution of MMPs and TIMPs to the marked endometrial remodelling associated with early placentation (Salamonsen et al. 1995).

\section{Modulation of the maternal immune system}

A stringent regulation of the maternal immune system is very important to protect the conceptus, which can be seen as a semi-allograft. Several genes were identified, which are probably involved in this process. The multifunctional protein galectin-9 was shown to induce apoptosis of various immune cells, including activated $\mathrm{CD}^{+}$and $\mathrm{CD}^{+}{ }^{+} \mathrm{T}$-cells, through the $\mathrm{Ca}^{2+}$-calpaincaspase-1 pathway, indicating a role in immune modulation by inducing apoptosis of these cells (Hirashima et al. 2004). However, in contrast to galectin-9, LGALS3BP has been shown to stimulate natural killer (NK) cell and lymphokine-activated killer cell activity (Ullrich et al. 1994). CD81 is reported to influence activation, proliferation and differentiation of $\mathrm{B}, \mathrm{T}$ and other cells. Furthermore, association with IFITM1 (Leu-13, 9-27) protein was shown on B-cells (Levy et al. 1998). IFITM1 itself was shown to suppress the activity of NK cells (Yang et al. 2005), suggesting a role in preventing maternal rejection of the fetal semi-allograft. BST2 was suggested to be involved in preB-cell growth (Ishikawa et al. 1995). The in situ hybridisation results revealed strongest expression in stromal cells. The upregulation of the mRNAs coding for the complement components $\mathrm{C} 1 \mathrm{R}$ and $\mathrm{C} 4 \mathrm{~A}$ and the $\mathrm{C} 1$ inhibitor SERPING1 (Ratnoff et al. 1969) reflects the regulation of the complement cascade. Co-localisation of $C 1 R, C 1 S$ and SERPING1 mRNA in the endometrium of day 18 pregnant cows was previously shown (Klein et al. 2006).

\section{Comparison to similar studies in cattle and sheep and related studies in humans, mice and primates}

The comparison of the known genes with our recent study of monozygotic twin cows (Klein et al. 2006) revealed a substantial and consistent overlap confirming the reliability of the results. For this comparison, it has to be considered that in Klein et al., a different biological model was used. Moreover, in addition to SSH, a second subtraction technique was applied, and different statistical analyses were conducted in Klein et al. In the study of ovine endometrium (Gray et al. 2006), the effects of IFNT and progesterone on gene expression were analysed in addition to the investigation of day 14 pregnant vs control ewes. Overall, 23 genes were found to overlap between the ovine and the present study. The expression of genes with higher mRNA levels in the bovine endometrium of pregnant animals was mostly detected as IFNT-dependent. The consistency of differential gene expression between cattle and sheep reflects similar mechanisms of pregnancy recognition and similar type of placentation of these two species.

Despite the distinct differences in the biology of reproduction between mammalian species, some genes could be identified, which were regulated similarly in the bovine endometrium compared to the endometrium of humans and rhesus monkey during the putative window of implantation or the mouse at the implantation stage respectively. Therefore, some common regulatory processes in these species can be suggested. For example, $D K K 1$, coding for an inhibitor of WNT signalling (Glinka et al. 1998), has been found as induced in four human studies at the window of implantation time. In bovine endometrium, DKK1 mRNA was 12-fold upregulated in the endometrium of pregnant animals. Likewise, for CLDN4, higher mRNA levels were detected in human endometrial tissue samples in four studies and in bovine endometrium. Elevated mRNA levels were also found in two human studies for P8, SLC1A1 and C10orf10 (DEPP), coding for a protein that is suggested to modulate the effects of progesterone during decidualisation (Watanabe et al. 2005). There may also be some common regulations of the maternal immune system indicated by the consistent regulation of C1R, SERPING1 and TAP1. Furthermore, $T G M 2$, coding for a protein involved in cell adhesion and ECM remodelling (see above), was shown to be upregulated in the human endometrium during the window of implantation. Comparable regulation in other species was found for a number of downregulated genes as well.

In conclusion, this comprehensive study of transcriptome changes in bovine endometrium at the preimplantation stage revealed a set of very promising candidate genes involved in crucial biological processes like cell adhesion, endometrial remodelling, regulation of the maternal immune system and the response to IFNT, the embryonic pregnancy recognition signal. Furthermore, with the set of genes identified in the present and our previous studies (Bauersachs et al. 2005, Klein et al. 2006) pregnancy signalling in bovine endometrium can also be compared between normal and pathological states or in vivo derived and in vitro produced embryos.

\section{Acknowledgements}

This study was supported by the German Research Foundation (FOR 478/1). The authors declare that there is no conflict of interest that would prejudice the impartiality of this scientific work. 


\section{References}

Ace CI \& Okulicz WC 2004 Microarray profiling of progesteroneregulated endometrial genes during the rhesus monkey secretory phase. Reproductive Biology and Endocrinology 254.

Ame JC, Spenlehauer C \& de Murcia G 2004 The PARP superfamily. Bioessays 26 882-893.

Austin KJ, Carr AL, Pru JK, Hearne CE, George EL, Belden EL \& Hansen TR 2004 Localization of ISG15 and conjugated proteins in bovine endometrium using immunohistochemistry and electron microscopy. Endocrinology 145 967-975.

Bauersachs S, Blum H, Mallok S, Wenigerkind H, Rief S, Prelle K \& Wolf E 2003 Regulation of ipsilateral and contralateral bovine oviduct epithelial cell function in the postovulation period: a transcriptomics approach. Biology of Reproduction 68 1170-1177.

Bauersachs S, Rehfeld S, Ulbrich SE, Mallok S, Prelle K, Wenigerkind H, Einspanier R, Blum H \& Wolf E 2004 Monitoring gene expression changes in bovine oviduct epithelial cells during the oestrous cycle. Journal of Molecular Endocrinology 32 449-466.

Bauersachs S, Ulbrich SE, Gross K, Schmidt SE, Meyer HH, Einspanier $R$, Wenigerkind $H$, Vermehren $M$, Blum $H$, Sinowatz $F$ \& Wolf $E$ 2005 Gene expression profiling of bovine endometrium during the oestrous cycle: detection of molecular pathways involved in functional changes. Journal of Molecular Endocrinology 34 889-908.

Bazer FW, Spencer TE \& Ott TL 1997 Interferon tau: a novel pregnancy recognition signal. American Journal of Reproductive Immunology $37412-420$.

Bezakova G \& Ruegg MA 2003 New insights into the roles of agrin. Nature Reviews. Molecular Cell Biology 4 295-308.

Binelli M, Subramaniam P, Diaz T, Johnson GA, Hansen TR, Badinga L \& Thatcher WW 2001 Bovine interferon-tau stimulates the Janus kinase-signal transducer and activator of transcription pathway in bovine endometrial epithelial cells. Biology of Reproduction 64 654-665.

Borthwick JM, Charnock-Jones DS, Tom BD, Hull ML, Teirney R, Phillips SC \& Smith SK 2003 Determination of the transcript profile of human endometrium. Molecular Human Reproduction $\mathbf{9}$ 19-33.

Carson DD, Lagow E, Thathiah A, Al Shami R, Farach-Carson MC, Vernon M, Yuan L, Fritz MA \& Lessey B 2002 Changes in gene expression during the early to mid-luteal (receptive phase) transition in human endometrium detected by high-density microarray screening. Molecular Human Reproduction 8 871-879.

Chen C, Spencer TE \& Bazer FW 2000 Expression of hepatocyte growth factor and its receptor c-met in the ovine uterus. Biology of Reproduction 62 1844-1850.

Chen JM, Fortunato M, Stevens RA \& Barrett AJ 2001 Activation of progelatinase $A$ by mammalian legumain, a recently discovered cysteine proteinase. Biological Chemistry 382 777-783.

Chu K \& Zingg HH 1997 The nuclear orphan receptors COUP-TFII and Ear-2 act as silencers of the human oxytocin gene promoter. Journal of Molecular Endocrinology 19 163-172.

de Veer MJ, Holko M, Frevel M, Walker E, Der S, Paranjape JM, Silverman RH \& Williams BR 2001 Functional classification of interferon-stimulated genes identified using microarrays. Journal of Leukocyte Biology 69 912-920.

Diatchenko L, Lau YF, Campbell AP, Chenchik A, Moqadam F, Huang B, Lukyanov S, Lukyanov K, Gurskaya N, Sverdlov ED \& Siebert PD 1996 Suppression subtractive hybridization: a method for generating differentially regulated or tissue-specific cDNA probes and libraries. PNAS 93 6025-6030.

Evans SS, Collea RP, Leasure JA \& Lee DB 1993 IFN-alpha induces homotypic adhesion and Leu-13 expression in human B lymphoid cells. Journal of Immunology 150 736-747.

Fesus L \& Piacentini M 2002 Transglutaminase 2: an enigmatic enzyme with diverse functions. Trends in Biochemical Sciences 27 534-539.
Glinka A, Wu W, Delius H, Monaghan AP, Blumenstock C \& Niehrs C 1998 Dickkopf-1 is a member of a new family of secreted proteins and functions in head induction. Nature 391 357-362.

Gray CA, Abbey CA, Beremand PD, Choi Y, Farmer JL, Adelson DL, Thomas TL, Bazer FW \& Spencer TE 2006 Identification of endometrial genes regulated by early pregnancy, progesterone, and interferon tau in the ovine uterus. Biology of Reproduction $\mathbf{7 4}$ 383-394.

Gray CA, Adelson DL, Bazer FW, Burghardt RC, Meeusen EN \& Spencer TE 2004 Discovery and characterization of an epithelialspecific galectin in the endometrium that forms crystals in the trophectoderm. PNAS 101 7982-7987.

Hicks BA, Etter SJ, Carnahan KG, Joyce MM, Assiri AA, Carling SJ, Kodali K, Johnson GA, Hansen TR, Mirando MA, Woods GL, Vanderwall DK \& Ott TL 2003 Expression of the uterine Mx protein in cyclic and pregnant cows, gilts, and mares. Journal of Animal Science 81 1552-1561.

Hirashima M, Kashio Y, Nishi N, Yamauchi A, Imaizumi TA, Kageshita T, Saita N \& Nakamura T 2004 Galectin-9 in physiological and pathological conditions. Glycoconjugate Journal 19 593-600.

Ho HS, Young NH, Yoon LJ, Chan GM, Hoon KC \& Kyoo KM 2004 Analysis of estrogen-regulated genes in mouse uterus using cDNA microarray and laser capture microdissection. Journal of Endocrinology 181 157-167.

Ishikawa J, Kaisho T, Tomizawa H, Lee BO, Kobune Y, Inazawa J, Oritani K, Itoh M, Ochi T, Ishihara K et al. 1995 Molecular cloning and chromosomal mapping of a bone marrow stromal cell surface gene, BST2, that may be involved in pre-B-cell growth. Genomics 26 527-534.

Johnson GA, Austin KJ, Collins AM, Murdoch WJ \& Hansen TR 1999 Endometrial ISG17 mRNA and a related mRNA are induced by interferon-tau and localized to glandular epithelial and stromal cells from pregnant cows. Endocrinology 10 243-252.

Kao LC, Tulac S, Lobo S, Imani B, Yang JP, Germeyer A, Osteen K, Taylor RN, Lessey BA \& Giudice LC 2002 Global gene profiling in human endometrium during the window of implantation. Endocrinology 143 2119-2138.

Kaushal GP, Walker PD \& Shah SV 1994 An old enzyme with a new function: purification and characterization of a distinct matrixdegrading metalloproteinase in rat kidney cortex and its identification as meprin. Journal of Cell Biology 126 1319-1327.

King AE, Critchley HO \& Kelly RW 2001 The NF-kappaB pathway in human endometrium and first trimester decidua. Molecular Human Reproduction 7 175-183.

Klein C, Bauersachs S, Ulbrich SE, Einspanier R, Meyer HH, Schmidt SE, Reichenbach HD, Vermehren M, Sinowatz F, Blum H \& Wolf E 2006 Monozygotic twin model reveals novel embryo-induced transcriptome changes of bovine endometrium in the preattachment period. Biology of Reproduction 74 253-264.

Kwak JC, Ongusaha PP, Ouchi T \& Lee SW 2003 IFI16 as a negative regulator in the regulation of p53 and p21(Waf1). Journal of Biological Chemistry 278 40899-40904.

Levy S, Todd SC \& Maecker HT 1998 CD81(TAPA-1):, a molecule involved in signal transduction and cell adhesion in the immune system. Annual Review of Immunology 16 89-109.

Li J \& Roberts RM 1994 Interferon-tau and interferon-alpha interact with the same receptors in bovine endometrium. Use of a readily iodinatable form of recombinant interferon-tau for binding studies. Journal of Biological Chemistry 269 13544-13550.

Liston P, Fong WG, Kelly NL, Toji S, Miyazaki T, Conte D, Tamai K, Craig CG, McBurney MW \& Korneluk RG 2001 Identification of XAF1 as an antagonist of XIAP anti-Caspase activity. Nature Cell Biology 3 128-133.

Livak KJ \& Schmittgen TD 2001 Analysis of relative gene expression data using real-time quantitative PCR and the 2(-Delta Delta C(T)) Method. Methods 25 402-408.

MacFarlane M, Merrison W, Bratton SB \& Cohen GM 2002 Proteasome-mediated degradation of Smac during apoptosis: XIAP 
promotes Smac ubiquitination in vitro. Journal of Biological Chemistry 277 36611-36616.

Martal JL, Chene NM, Huynh LP, L'Haridon RM, Reinaud PB, Guillomot MW, Charlier MA \& Charpigny SY 1998 IFN-t, tau: a novel subtype I IFN1. Structural characteristics, non-ubiquitous expression, structure-function relationships, a pregnancy hormonal embryonic signal and cross-species therapeutic potentialities. Biochimie 80 755-777.

Mirkin S, Arslan M, Churikov D, Corica A, Diaz JI, Williams S, Bocca S \& Oehninger S 2005 In search of candidate genes critically expressed in the human endometrium during the window of implantation. Human Reproduction 20 2104-2117.

Nakamura H, Kimura T, Ogita K, Koyama S, Tsujie T, Tsutsui T, Shimoya K, Koyama M, Kaneda Y \& Murata Y 2004 Alteration of the timing of implantation by in vivo gene transfer: delay of implantation by suppression of nuclear factor kappaB activity and partial rescue by leukemia inhibitory factor. Biochemical and Biophysical Research Communications 321 886-892.

Ng CC, Arakawa H, Fukuda S, Kondoh H \& Nakamura Y 2003 p53RFP, a p53-inducible RING-finger protein, regulates the stability of p21WAF1. Oncogene 22 4449-4458.

Prakash BS, Meyer HH, Schallenberger E \& van de Wiel DF 1987 Development of a sensitive enzymeimmunoassay (EIA) for progesterone determination in unextracted bovine plasma using the second antibody technique. Journal of Steroid Biochemistry $\mathbf{2 8}$ 623-627.

Pru JK, Austin KJ, Haas AL \& Hansen TR 2001 Pregnancy and interferon-tau upregulate gene expression of members of the 1-8 family in the bovine uterus. Biology of Reproduction 65 1471-1480.

Ratnoff OD, Pensky J, Ogston D \& Naff GB 1969 The inhibition of plasmin, plasma kallikrein, plasma permeability factor, and the $C^{\prime} 1 \mathrm{r}$ subcomponent of the first component of complement by serum $C^{\prime} 1$ esterase inhibitor. Journal of Experimental Medicine 129 315-331.

Reese J, Das SK, Paria BC, Lim H, Song H, Matsumoto H, Knudtson KL, DuBois RN \& Dey SK 2001 Global gene expression analysis to identify molecular markers of uterine receptivity and embryo implantation. Journal of Biological Chemistry 276 44137-44145.

Rempel LA, Francis BR, Austin KJ \& Hansen TR 2005 Isolation and sequence of an interferon-tau-inducible, pregnancy- and bovine interferon-stimulated gene product 15 (ISG15)-specific, bovine ubiquitin-activating E1-like (UBE1L) enzyme. Biology of Reproduction 72 365-372.

Riesewijk A, Martin J, van Os R, Horcajadas JA, Polman J, Pellicer A, Mosselman S \& Simon C 2003 Gene expression profiling of human endometrial receptivity on days $\mathrm{LH}+2$ versus $\mathrm{LH}+7$ by microarray technology. Molecular Human Reproduction 9 253-264.

Roberts RM, Ealy AD, Alexenko AP, Han CS \& Ezashi T 1999 Trophoblast interferons. Placenta 20 259-264.

Salamonsen LA, Nagase H \& Woolley DE 1995 Matrix metalloproteinases and their tissue inhibitors at the ovine trophoblast-uterine interface. Journal of Reproduction and Fertility (Supplement) 49 29-37.

Sasaki T, Brakebusch C, Engel J \& Timpl R 1998 Mac-2 binding protein is a cell-adhesive protein of the extracellular matrix which selfassembles into ring-like structures and binds beta1 integrins, collagens and fibronectin. EMBO Journal 17 1606-1613.

Spencer TE \& Bazer FW 1996 Ovine interferon tau suppresses transcription of the estrogen receptor and oxytocin receptor genes in the ovine endometrium. Endocrinology 137 1144-1147.
Stewart DM, Johnson GA, Vyhlidal CA, Burghardt RC, Safe SH, Yu-Lee LY, Bazer FW \& Spencer TE 2001 Interferon-tau activates multiple signal transducer and activator of transcription proteins and has complex effects on interferon-responsive gene transcription in ovine endometrial epithelial cells. Endocrinology 142 98-107.

Sun XY, Li FX, Li J, Tan YF, Piao YS, Tang S \& Wang YL 2004 Determination of genes involved in the early process of embryonic implantation in rhesus monkey (Macaca mulatta) by suppression subtractive hybridization. Biology of Reproduction $\mathbf{7 0}$ 1365-1373.

Takamoto N, Kurihara I, Lee K, DeMayo FJ, Tsai MJ \& Tsai SY 2005 Haploinsufficiency of chicken ovalbumin upstream promoter transcription factor II in female reproduction. Journal of Molecular Endocrinology 19 2299-2308.

Takeda N, Maemura K, Imai Y, Harada T, Kawanami D, Nojiri T, Manabe I \& Nagai R 2004 Endothelial PAS domain protein 1 gene promotes angiogenesis through the transactivation of both vascular endothelial growth factor and its receptor, Flt-1. Circulation Research 95 146-153.

Takeyama K, Aguiar RC, Gu L, He C, Freeman GJ, Kutok JL, Aster JC \& Shipp MA 2003 The BAL-binding protein BBAP and related Deltex family members exhibit ubiquitin-protein isopeptide ligase activity. Journal of Biological Chemistry 278 21930-21937.

Thatcher WW, Guzeloglu A, Mattos R, Binelli M, Hansen TR \& Pru JK 2001 Uterine-conceptus interactions and reproductive failure in cattle. Theriogenology 56 1435-1450.

Tsukita S \& Furuse M 2002 Claudin-based barrier in simple and stratified cellular sheets. Current Opinion in Cell Biology 14 531-536.

Tusher VG, Tibshirani R \& Chu G 2001 Significance analysis of microarrays applied to the ionizing radiation response. PNAS $\mathbf{9 8}$ 5116-5121.

Ullrich A, Sures I, D'Egidio M, Jallal B, Powell TJ, Herbst R, Dreps A, Azam M, Rubinstein M \& Natoli C 1994 The secreted tumorassociated antigen $90 \mathrm{~K}$ is a potent immune stimulator. Journal of Biological Chemistry 269 18401-18407.

Watanabe H, Nonoguchi K, Sakurai T, Masuda T, Itoh K \& Fujita J 2005 A novel protein Depp, which is induced by progesterone in human endometrial stromal cells activates Elk-1 transcription factor. Molecular Human Reproduction 11 471-476.

Wolf E, Arnold GJ, Bauersachs S, Beier HM, Blum H, Einspanier R, Frohlich T, Herrler A, Hiendleder S, Kolle S, Prelle K, Reichenbach HD, Stojkovic M, Wenigerkind H \& Sinowatz F 2003 Embryo-maternal communication in bovine-strategies for deciphering a complex cross-talk. Reproduction in Domestic Animals 38 276-289.

Yang Y, Lee JH, Kim KY, Song HK, Kim JK, Yoon SR, Cho D, Song KS, Lee YH \& Choi I 2005 The interferon-inducible 9-27 gene modulates the susceptibility to natural killer cells and the invasiveness of gastric cancer cells. Cancer Letters 221 191-200.

Zhang B, Schmoyer D, Kirov S \& Snoddy J 2004 GOTree Machine (GOTM): a web-based platform for interpreting sets of interesting genes using Gene Ontology hierarchies. BMC Bioinformatics 516.

Received 5 October 2005

First decision 6 December 2005

Revised manuscript received 2 March 2006

Accepted 31 March 2006 